РЕАБИЛИТАЦИЯ БОЛЬНЫХ С ПАТОЛОГИЕЙ ОРГАНА ЗРЕНИЯ В УСЛОВИЯХ ОФТАЛЬМОЛОГИЧЕСКОГО КАБИНЕТА С ПОМОЩЬЮ ЛАЗЕРНОГО ВОЗДЕЙСТВИЯ.

Иванов А.Н., Алексеева И.Б., Танковский В.Э. ФГБУ "МНИИГБ им. Гельмгольияа" МЗ РФ, Москва. Иванов Андрей Николаевич (1) старший научный сотрудник, дмн, отдел травматологии и реконструктивной хирургии; Алексеева Ирина Борисовна (1) старший научный сотрудник, кмн, отдел травматологии и реконструктивной хирургии; Танковский Владимир Эдуардович (2) старший научный сотрудник, дмн, отдел патологии сетчатки.

DOI: $10.31618 /$ ESU.2413-9335.2019.2.58.36-40

АННОТАЦИЯ. Представленная работа посвящена организации реабилитации больных с патологией органа зрения в условии лазерного кабинета. Проведение различных лазерный операция и терапевтического воздействия. Представлены аннотации 17 лазерных операция, захватывающих все оболочки глазного яблока.

Ключевые слова. ИАГ-лазерная хирургия, реабилитация больных с патологией глаза.

\title{
REHABILITATION OF PATIENTS WITH PATHOLOGY OF THE ORGAN OF VISION IN CONDITIONS EYE CLINIC WITH LASER TREATMENT.
}

Ivanov A.N., Alekseeva I.B., Tankovsky V.E.

Ivanov Andrey Nikolayevich (1) department of injuries and reconstruction eye surgery MNII eye disease Helmholtz doctor of medical sciences, senior research Alekseeva Irina Borisovna department of injuries and reconstruction eye surgery MNII eye disease Helmholtz candidate of medical sciences, senior researchю Tankovsky Vladimir Eduardovich department of retina pathology MNII eye disease Helmholtz doctor of medical sciences, senior research

ANNOTATION. The presented work is devoted to the organization of rehabilitation of patients with pathology of the organ of vision in the laser room. Carrying out various laser surgery and therapeutic effects. There are 17 laser surgery annotations covering all the eyeball shells.

Keyword. YAG-laser surgery, rehabilitation of patients with eye pathology.

Механическая травма глаза и реабилитация её последствий является одной из актуальных проблем офтальмотравматологии, связанных с последствиями хирургических и травматических проникающих ранений, в том числе с внедрением инородного тела, а также контузией глазного яблока.

С 1990 г. травма глаза в России вышла на первое место в структуре причин инвалидности по зрению, составив 19-22\% первичных инвалидов. Механическая травма составляет $70 \%$ от всех случаев повреждения глаза.

Орган зрения страдает при бытовом травматизме в 6-8\% случаев, катастрофах и чрезвычайных ситуациях - 4-7\%, боевых действиях в 5-10\% случаев.

Тяжесть травмы определяется локализацией и размером раны, степенью повреждения и потерей стекловидного тела, расположением кровоизлияния внутри глаза, а также от развития помутнения оптических структур глаза, фиброзных изменений. Основной вид реабилитации при травме глаза - операции, в которых стремятся к максимальному восстановлению поврежденных структур глаза. Инфекции, синехии и шварты, рубцовые дистрофии, отслойка и металлоз оболочек вызывают комплекс изменений, который не всегда удается скорректировать.

Существующие в настоящее время оперативно-инструментальные способы лечения не дают ожидаемого результата в 19-83\% случаях, в зависимости от того в какой мере удается сохранить и восстановить анатомическую целость структуры и оптическую систему глазного яблока, предотвратить нарушение метаболизма и связанную с этим избыточную пролиферацию и фиброз в поврежденных тканях.

Лазерное излучение - уникальный инструмент в микрохирургии глаза, позволивший заменить “ножевую" хирургию более атравматичными лазерными операциями, которые подразделяют на реабилитационные, корригирующие, комбинированные лазерно-инструментальные операции, а также подготовительные для инструментальных вмешательств.

Их можно осуществлять поэтапно, более чаще в амбулаторных, чем в условиях стационара. Пациенты, которым проводят лазерные вмешательства, отмечают эмоциональное и физическое спокойствие в момент лазерной операции, отсутствие побочных эффектов.

Лазерные воздействия различают: по функциональному типу лазера - коагулирующая терапия, основанная на термическом действии лазерного излучения; лазерная хирургия, использующая механическую энергию импульсов, излучаемых лазерами-деструкторами; стимулирующая лазерная терапия с активацией репаративных процессов под 
действием расфокусированного низкоинтенсивного излучения; диагностическая лазерная процедура; по типу доставки к внутренним структурам глазного яблока: транспупиллярные; трансконъюнктивальные или транссклеральные; эндолазерные; по задачам воздействия - рефракционная роговичная хирургия; восстановительная или реконструктивная лазерная хирургия, включающая оптические, профилактические и реконструктивные операции, в том числе микрохирургия глаукомы; эндолазерная хирургия, основанная на использовании оптических проводников и волоконной оптики; экстраокулярная хирургия с использованием углекислого лазерного скальпеля, аргонового и диодного лазера, НИАГ-лазера; стимуляция и регенерация тканей; по срокам воздействия: ургентная и плановая.

Лазер, характеризующийся одними и теми же физическими параметрами излучения, может использоваться для различных целей. Например, $\mathrm{Nd}: \mathrm{YAG}$ лазер с фотоабляционным действием при использовании световода превращается в эндолазерный скальпель, одинаково эффективно разрушающий хрусталик и стекловидное тело.

Имеется огромный опыт по проведению лазерных вмешательств, как в первые часы, так и в длительный период после травмы (более 10 лет) (А.В. Большунов, 1993-1999; П.И. Сапрыкин, 1971-1986; А.Д. Семенов с соавт., 1984-1989; А.В. Степанов, 1987-2002; Э.В. Егорова с соавт., 1986; Я.Д. Кулаков, 1986; В.В. Нероев, 1992; Е. Okun, 1974; D. Aron-Rosa, 1981; F. Fankhauser, 1985). Однако на данном этапе развития лазерной офтальмологии нами представляется около 100 инструментальных вмешательств, которые можно заменить на лазерные и лазерно-оперативные вмешательства.

Кроме вышеуказанного, следует в очередной раз напомнить о сокращении сроков консервативного лечения до 2-6 раз у больных после лазерного лечения относительно инструментального, перевод стационарных видов вмешательств в лазерные амбулаторные и, тем самым, наблюдается экономия коек, времени и финансов для реабилитации данного контингента больных.

Создание лазерного кабинета в условиях районной поликлиники под силу даже бюджетной организации, а объем проводимых вмешательств будет не меньше специализированного стационара.

Необходимое оборудование и рекомендации проведения лазерного воздействия. Источник лазерного излучения может быть представлен, как отечественным, так и импортным оборудованием: с неодимиевым ИАГ-лазерным перфоратором (длина волны 1064 нм); коагулятором - аргоновым (длина волны 492-510 нм) или диодным (длина волны 810 нм).

Лазерный комбайн наиболее оптимален для оперативного применения. При этом доставка излучения осуществляется транспапуллярно под контролем контактных линз, транссклерально и в некоторых случаях используют эндолазерное воздействие с помощью стекловолокна. Вместо геля для контактных линз можно использовать солкосериловое (актовегиновое) желе.

Кроме этого, обязательно присутствуют приборы для проведения асептики и средства для антисептики, имеющиеся в хирургическом кабинете.

При планировании лазерной операции учитывается прозрачность оптических сред, взвесь во влаге передней камеры и возможная ответная реакция парного глаза на воздействие, почти полностью совпадающей по степени, силе и характеру колебаний физиологических показателей оперируемого.

Начальная энергия - минимальнейшая, с увеличения мощности импульса риск осложнений возрастает. Повышение ВГД зависит от энергии воздействия.

Перед лазерной операции больной должен пройти психологическую подготовку, в ряде случаев рекомендуется седативная терапия; целесообразно проводить инстилляционную анестезию; беспокойным больным - ретробульбарную анестезию.

Контактная линза способствует адекватному наведению фокуса, требует меньшего энергетического воздействия, ограничивает подвижность глазного яблока и располагает больного к спокойному поведению в момент процедуры и обеспечивает адекватный подход к зоне вмешательства.

Все типы ИОЛ могут быть повреждены ИАГлазерным импульсом. Формовочные линзы (мягкие) более адаптированы к повреждению, а стеклянные линзы раскалываются. Более опасен мультиимпульсный режим неодимиевого лазера типа mode-locked, чем Q-switched.

Для профилактики осложнений рекомендуют подготовку к лазерной операции, включающую помимо анестезии: седативные препараты за сутки до операции; диуретики перед операцией и в течение суток после неё; $\beta$-блокаторы в инстилляциях перед операцией и 1-5 суток после неё, а также иммунодепрессанты в виде глазных капель или внутрь в течение всего реактивного периода; кортикостероиды и нестероидные противовоспалительные препараты 3-7 суток после лазерной операции. При возникновении осложнений длительность приема усиливают до 2-х раз, в том числе применяют субконъюнктивальные и ретробульбарные инъекции стероидов, а также симптоматическую терапию.

Далее разрешите представить ряд оперативнолазерных вмешательств, которые легко осуществляют в амбулаторных условиях.

Устранение посттравматической патологии конъюнктивы с помощью инструментальных методик ведёт к излишней травматизации слизистой оболочки глазного яблока.

Применение разработанных лазерных методик исключает такие осложнения как кровотечение, смещение или ущемление осколка в ране конъюнктивы, которые были подтверждены среди 65 пациентов.

При кисте конъюнктивы или для обнажения инородного тела из-под конъюнктивы лазерное воздействие выполнять под инстилляционной анестезией деструктивным ИАГ-лазерным воздействием на внутреннюю часть кисты с образованием 
кавитационной полости или "пузырей", заполняющих кисту и создающих повышенное напряжение наружной стенки кисты (этот прием позволяет не смыкаться стенкам кисты после её вскрытия), либо по поверхности кисты или над инородным телом, либо подковообразным вскрытием по основанию. При недостаточности вскрытия целесообразно провести лазерную коагуляцию оставшейся конъюнктивальной ткани для её сокращения с захватом "дна" кисты (появившаяся кровь усиливает эффект коагуляции прозрачной конъюнктивы). Энергия неодимиевого ИАГ-лазерного воздействия от 3,4 до 9,5 mJ, количество импульсов 32-112; энергия коагуляции - 0,4-1,3 W, количество аппликаций 8-67.

Коррекцию деформации роговицы, индуцированной шовным материалом, осуществляют инструментальными и лазерными методами по всей поверхности роговицы: так называемые "насечки" и абляция роговичной ткани. В том и другом случае устранение выявленной патологии происходит в поздний послеоперационный период, когда роговичные швы сняты и стабилизировано состояние рубца роговицы.

У 282 пациента мы провели локальное лазерное пересечение шовного материала в строме роговицы для устранения роговичного астигматизма через 8-16 недель после наложения, ИАГ-лазерным деструктивным и коагулирующим пересечением шва роговицы с минимальным количеством импульсов для избежания чрезмерного повреждения роговичной ткани. Установлено, что диодное лазерное воздействие более эффективно, чем аргоновое при отечной роговице.

Для облегчения воздействия фокус рекомендуем наводить на участок наиболее выраженного натяжения шва и астигматического изменения. Энергия ИАГ-лазерного воздействия от 0,5 до 4,0 $\mathrm{mJ}$, коагуляции - 0,2-0,5 W, количество импульсов $1-15$.

Эффект разрушения или пересечения швов в строме роговицы достигнут во всех случаях за 1 сеанс лазерной процедуры, после которого по данным кератометрического исследования астигматизм уменьшился на $0,75-6,0^{\mathrm{D}}$. Решение о повторном воздействии на шовный материал целесообразно принимать через 3-4 часа после обработки, так как ослабление всего шва наблюдается не сразу.

Для утилизации частей шовного материала, выступающих над поверхностью роговой оболочки и вызывающих дистрофию и неоваскуляризацию роговицы, у 175 пациентов выполнялась лазерная или эндолазерная коагуляция, деструкция ИАГ-лазером или их комбинации под инстилляционной анестезией. У подобных больных инструментальное удаление остаточного шовного материала происходит с повреждением роговицы, выраженным кровотечением из новообразованных сосудов.

При дегенерации роговой оболочки, вызванной шовным материалом, воздействовать неодимиевым ИАГ-лазерным излучением на границе с роговицей, коагулирующим - с дистального края или под основание; эндолазерным наконечником коагулировать под основание шва.

Энергия ИАГ-лазерного импульса составляла около 1,5-6,0 mJ, коагуляции до 0,6 W. Количество импульсов не превышало 15 при ИАГ-лазерном воздействии, а при коагуляции - 4 .

Запланированный результат достигнут во всех случаях, и после устранения раздражающего фактора, состояние роговицы улучшилось - исчезла неоваскуляризация, восстановился эпителий.

Ретрокорнеальная мембрана возникает после травм органа зрения, внутриглазных операций и значительно снижает остроту зрения. Её относят к патологии роговой оболочки, хотя причинами её образования чаще всего являются изменения передней камеры. Ретрокорнеальная мембрана была у 45 пациентов в виде белесоватого образования на задней поверхности роговицы, непосредственно имеющего контакт с эндотелием роговицы или задней поверхностью кератопротеза. С целью реконструкции передней камеры выполняли ИАГ-лазерное ударное воздействие или непосредственно на мембрану на слабом энергетическом режиме до 4,0 mJ, или опосредованно со стороны передней камеры путём создания гидродинамической волны с использованием поэтапной нефокусированной деструкции возможного повышения уровня энергии до 6,0-9,0 mJ. Энергия воздействия зависела от прозрачности роговой оболочки, плотности и распространенности мембраны в передней камере, площади контакта с задней поверхностью роговицы и подбиралась индивидуально, начиная с минимальной по воздействию.

После операции освобождается поверхность роговицы с восстановлением её прозрачности, а разрушенные элементы мембраны лизируются. Представленная методика позволила достичь повышения остроты зрения у 86,7\% больных. Для более адекватного и безопасного лазерного разрушения мембраны использовали контактную линзу для воздействия на передний отрезок.

Контакт роговицы с радужкой ведет к изменению роговицы, поэтому устранение ущемления радужки в ране роговицы является необходимой реконструктивной операцией.

Для выведения ущемленной радужки из раны роговицы или трабекулярной зоны мы направляли гидродинамическую волну ИАГ-лазерного импульса у 118 больных на ткань радужки в зоне ущемления с минимальной энергией до 2,0-3,0 mJ (лазерный массаж) в ранние послеоперационные сроки от 10 часов до 21 суток. В целях усиления лазерного воздействия применяли миотики или мидриатики, в зависимости от локализации ущемления. В 46 случаях для оказания необходимого усилия потребовался один импульс. При подобном лазерном воздействии не отмечено расхождение свежего рубца роговицы, в отличие от инструментального воздействия.

При заращении радужки в рубце роговицы рекомендована эндолазерная резекции заращенной радужки в рубце роговицы, которую применили у 5 
пациентов в сроки от 1 месяца до 5 лет. При эндолазерной коагуляции наконечник эндолазера использовали как дополнительное механическое средство для репозиции радужки при полостной операции, помогая наконечником эндолазера (боковой стороной) репозиции тканей. Энергия эндолазерного коагуляционного излучения составляла 0,2-0,8 W, количество аппликаций не превышало 12 ; при этом не наблюдалось внутриглазных кровотечений.

Подобного эффекта достигли при двухэтапной лазерной операции, состоящую из коагуляции радужки около роговичного рубца аргоновым лазером и отсечении её ИАГ-лазером в 58 случаях. Наблюдалось восстановление оптических функции глаза и анатомо-физиологическое соотношение структур передней камеры.

Фокус импульсного воздействия выводился непосредственно на точку ущемления радужки под контролем трехзеркальной линзы.

Киста передней камеры глазного яблока по мере роста деформирует окружающие ткани и вызывает их преобразование, способные привести глаз к гибели.

Нами использована тактика лазерного и оперативно-лазерного лечения у 41 пациента. Лазерный метод осуществлен без нарушения целостности фибринозной оболочки глаза, где под ИАГлазерным воздействием с энергией до 7,0 mJ отсекали кисту передней камеры с прозрачным содержимым ИАГ-лазерным воздействием у её основания после наполнения её ИАГ-лазерными кавитационными пузырями и появления вертикальной тяги. Освободившуюся зону роста кисты коагулируют лазерным воздействием через трехзеркальную линзу. Плавающую кисту в передней камере перфорировали ИАГ-лазером или коагулировали для уменьшения её размеров с последующим медикаментозным лизисом.

Представленная методика проста в исполнении, но при этом нужно постоянно поддерживать "плавучесть" кисты кавитационными пузырями.

Разработанная тактика позволяет устранить кисту с минимумом травматизации тканей глазного яблока и объема оперативного воздействия. Рецидив кистообразования после лазерной резекции отмечен в $12 \%$ случаев при обоих методах резекции.

Устранение осложнений проникающих антиглаукоматозных операций, которые чаще наблюдают при комбинации с экстракцией катаракты, обтурации фистулы выпотом, кровью или корнем радужной оболочки, остатками капсулы хрусталика.

Два варианта подобного лазерного воздействия на УПК позволили нормализовать внутриглазное давление у 37 пациентов.

1. Для устранения экссудата или кровоизлияния нами предложено использовать лазеры деструктивного (кровь, выпот) и/или коагулирующего действия (кровь) с одномоментным введением фибринолитического препарата субконъюнктивально или ретробульбарно до или непосредственно после лазерного воздействия, при этом сроки лизиса сокращались в 1,5-2 раза.

2. Ущемленную ткань радужки или капсульной сумки предложено выводить из фистулы трабекулярной зоны направленными ИАГ-лазерными импульсами, используя энергию ударной волны. При отсутствии эффекта целесообразно отсекать ИАГ-лазером их в зоне ущемления или коагулировать с целью сокращения и выведения радужной ткани.

Кровь, излившаяся в переднюю камеру или гифема через 5-7 дней превращается в сгусток, приводящий к обтурации УПК и имбибиции, дистрофии роговицы, вторичной гипертензии и неоваскуляризации оболочек.

Для её лечения мы предлагаем оказывать деструктивное ИАГ-лазерное воздействие с энергией до 7,0-9,0 mJ для фрагментации сгустков крови в передней камере (лазерный метод) и усиления лизиса добавлением фермента гемазы (лазерно-ферментативный метод). Эффект гемолиза наблюдается как при воздействии на кровь, так и на влагу передней камеры.

Метод применен для лечения 286 пациентов и включает в себя две методики.

1. Одна методика импульсного ИАГ-лазерного воздействия (лазерный метод), усиливает циркуляцию влаги и крови в передней камере, обеспечивает снижение агрегации кровяных элементов, постоянное перемешивание кровяных элементов и увеличение площади гемолитического действия даже после 14 суток от момента травмы.

2. При второй каждые 24 часа под конъюнктиву травмированного глаза делается инъекция препарата гемаза, растворенного в 0,5 мл раствора лидокаина; одновременно 4 раза в день осуществляется инстилляция глазных капель антибактериального и противовоспалительного действия (макситрол).

Время рассасывания кровоизлияния при первой методике от 3 до 15 суток, при добавлении гемазы - от 2 до 11 суток.

Подвывих интраокулярной линзы или несостоятельность её положения является отягощающим фактором и способны привести к дистрофии роговицы, вторичной глаукоме и т.д. Для фиксации ИОЛ из медикаментозных средств наиболее целесообразно применение миотиков пролонгированного действия, а из оперативных - подшивание ИОЛ, но, несмотря на стремление обеспечить дополнительную фиксацию, в 2-20\% наблюдается её дислокация. Реконструктивная хирургия при этом обладает выраженным травмирующим эффектом, а требования к повторному введению интраокулярной линзы высоки.

Для устранения сублюксации ИОЛ мы кардинально изменили подход к образованию спаек между радужкой и ИОЛ. 14 больным с ИКЛ проведена лазеркоагуляция радужки через зону фиксации дужки ИОЛ перпендикулярно к оптическому элементу. Дужка при этом служила проводником излучения, и коагуляция радужки происходила в 
точках контакта с дужкой. При этом радужная оболочка "обволакивает" дужку, а не сокращается как при прямом воздействии на неё, энергии коагуляции требовалось меньше, чем при прямом воздействии на радужку (0,3-0,6 W, количество аппликаций на одну дужку 2-6)

У 23 больных применена методика эндолазерной коагуляции. В 4 случаях после транспупиллярного воздействия сохранялось тенденция ИКЛ к сублюксации и проведена эндолазерная коагуляция радужки к частям ИКЛ. Эндолазерным наконечником восстанавливали положение ИОЛ и прижимали радужку к дужке с одновременной коагуляцией. У 2 пациентов после оперативно-лазерного воздействия развился увеит. В 19 случаях при наличии ЗКЛ производили эндолазеркоагуляцию через переднюю поверхность радужки. Энергия эндолазерного воздействия составила от 0,4 до $0,7 \mathrm{~W}$, количество аппликацией не превышало 15.

У больных с ЗКЛ наблюдалось стабильное положение в 16 случаях $(84,2 \%)$ в течение двух лет наблюдения, а при ИКЛ - в 78,6\% случаев.

Для поддержания ИОЛ на фоне противовоспалительного лечения использовали миотики - пилокарпин.

Лечение гемофтальма. Стекловидное тело пропитывается излившейся в полость глаза кровью, вызывая дистрофические изменения сетчатой оболочки, вторичную глаукому, катаракту. В лечении кровоизлияний стекловидного тела применяется медикаментозная терапия и хирургическое лечение - витрэктомия.

Лазерное лечение, предлагаемое нами, основано на проведении ИАГ-лазерного воздействия на стекловидное тело в режиме деструкции. Оно возможно, как обособленное воздействие ИАГлазерного излучения на стекловидное тело (лазерный метод) и совместное действие ИАГ-лазерного излучения с фибринолитиком (лазерно-ферментативный метод).

Лазерный метод проведен у 78 больных: энергия ИАГ-лазерного воздействия от 1,5 до 9,0 mJ, количество залпов от 20 до 80. Обычное число сеан- сов было 2-5, в ряде случаев число сеансов доходило до 10. Сеанс ИАГ-лазерного гематолизиса повторяли через 2-3 дня.

Лазерно-ферментативный метод использован у 48 больных. Схема применения представлена ранее при лечении гифемы.

Динамика гемолиза оценивалась по результатам УЗИ (А- и $\beta$-эхография). По данным квантитативной эхографии можно судить о более высокой литической способности лазерно-ферментативного метода - 92,3\%, тогда как при лазерном методе она составляла $73,3 \%$, а при традиционном - $28 \%$. Время рассасывания гемофтальма при ИАГлазерном лечении от 9 до 31 суток (в среднем 13,9 суток) и при лазерно-ферментативном 7-19 суток (в среднем 9,3 суток).

В результате проведенных ИАГ-лазерных и лазерно-ферментативных воздействий острота зрения улучшилась в $88,9 \%$ случаев. В контрольной - улучшение отмечено в $69,7 \%$.

В данной работе нами представлена только часть возможных манипуляций. Ведь с помощью лазерных методик можно заменить более 100 инструментальных операций.

Выводы: Применение лазерной хирургии решает актуальную задачу офтальмохирургии - проводить лечение почти всех проявлений механической травмы органа зрения (от конъюнктивы до заднего отдела глазного яблока), в том числе и послеоперационных осложнений, подготовительные вмешательства перед инструментальными операциями в большинстве случаев в амбулаторных условиях с меньшей травматизацией, с использованием минимального количества медикаментов и препаратов, а также сокращение сроков реабилитации больных в условиях лазерного комбинированного блока компактного военного или гражданского учреждения.

Литература.

1. Иванов А.Н. Система лазерно-инструментальной профилактики и лечения последствий и осложнений механической травмы глаза. Дисс. ... докт. мед. наук, - М., -2003, - 347 с. 